\title{
Application of Hybrid-Ihacres models for water availability in Siak River
}

\author{
Manyuk Fauzi ${ }^{1, *}$, Ermiyati ${ }^{1}$, Suprasman $^{1}$, Siswanto $^{1}$, Alfian Malik ${ }^{1}$, Doli Ananta Putra ${ }^{1}$, and \\ Andica Putra $^{1}$ \\ ${ }^{1}$ Department of Civil Engineering, Universitas Riau, Pekanbaru, Indonesia
}

\begin{abstract}
Watershed management with potential water resources greater than or equal to $20 \%$ of the potential of water resources in the province requires a device capable of addressing those needs. The Siak river area is a potential source of water resources greater than $20 \%$. Until now, the Siak river area does not yet have an integrated water resource information system; thus information on the potency of water absorption cannot be adequately recorded. Prediction of water availability in watersheds has significance for the management of a watershed. The research aims to develop a hydrological model to strengthen the water availability information to complete the water availability information. The built model is a combination of a conceptual model with wavelet (hybrid model) that is wavelet-ihacres. The wavelet transform method has the advantage of decomposing and reconstructing the data to produce better predictions. The results showed that the combined wavelet-ihacres have a coefficient correlation between observation data and output model of 0.737 . The value is classified as a strong correlation.
\end{abstract}

\section{Introduction}

Drought and flood events always come every year and occur in various locations. Factors that cause drought are almost the same as causes of flooding, and both have linear dependent behavior. This condition becomes a problem that must be resolved in the framework of water resources management. Management of water resources must be able to provide solutions to water resources problems that include problems concerning supply or availability and issues in terms of use. Thus the management of water resources must pay attention to the potential of existing water resources. The potential of water resources in the management concept is limited by a natural system known as the watershed.

Watershed management with the potential of water resources greater than or equal to $20 \%$ of the potential of water resources in the province requires devices that can answer these needs. One of the watersheds that have a potential higher than $20 \%$ is the Siak River. Until the Siak River basin does not yet have an integrated water resources information system. So that information about the potential for water deprivation cannot be

\footnotetext{
*Corresponding author: manyu fauzi@yahoo.com and manyuk.fauzi@unri.ac.id
} 
appropriately recorded. Prediction of water availability in the watershed has an essential meaning for the management of water resources.

To complete information on water availability, the research aims to develop a hydrological model to strengthen the information on water availability. The model built is a combination of conceptual models with artificial intelligence, namely wavelet-ihacres. The IHACRES model (Identification of Hydrograph and Component Flow Units from Rainfall, Evaporation and Stream Flow Data) was developed in the UK, describing flow rain into two sub-processes namely vertical sublateral processes and sub-processes [1]. Meanwhile, the wavelet transformation method has the advantage of decomposition and reconstruction of raw data in a time series that still has a hidden data pattern. Data that has been decomposed and reconstructed is denoise. Thus the concept of this merger is to improve the performance of predictions of water availability.

\section{Methodology}

\subsection{Research location}

Siak River basin is one of the major rivers that is included in the national strategic river criteria. The criteria of national strategic has the following parameters: a) the potential of water resources in the relevant river area is more significant or equal to $20 \%$ of the potential water-resource in the province; b) the number of resources sectors in the relevantriver basin is at least 16 (sixteen) sectors; and the number of population in the basin is at least $30 \%$ (thirty percent) of the total province population; d) the negative impact due to the destructive force of water to economic growth resulting in economic losses is at least $1 \%$ of gross regional domestic product of the province. In this study research, the location area is in upstream Siak basin, with outlet point at Pantai Cermin automatic water lever recorder station (see Fig. 1). Geographically Siak River basin is in the position between 100028'102012' East Longitude and 0020'-1016' North Latitude [2].

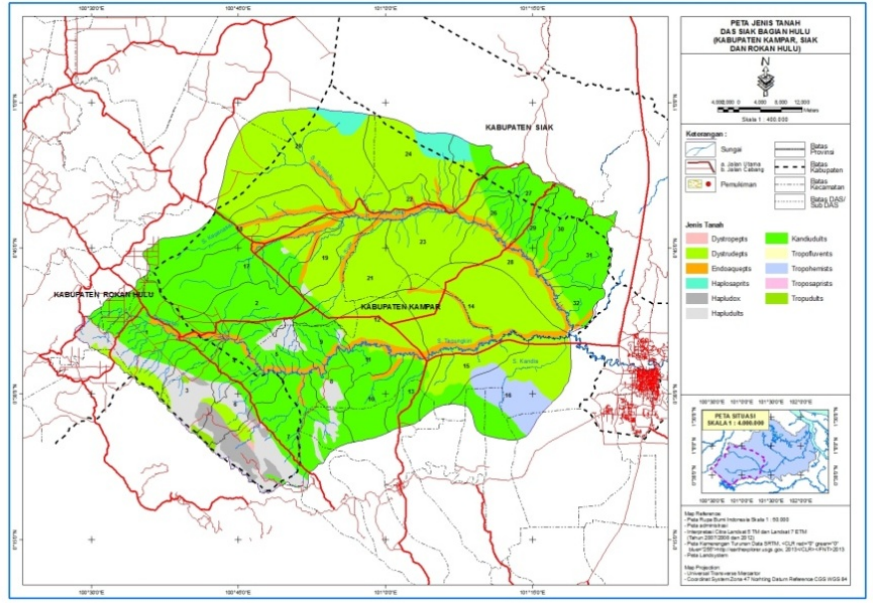

Fig. 1. Upstream area of Siak river basin.

\subsection{Wavelet transform}

Wavelet transformation is a conversion function that can be used to divide a function or signal into a different frequency component which can then be studied according to the 
scale resolution. Wavelet transforms divided into two major parts, namely continuous wavelet transformation and discrete wavelet transformation. Continuous wavelet Transformation has a way of working that is to calculate the convolution of a signal with a modulation window at any time with each desired scale. This modulation window that has a flexible range is called a mother wavelet or primary wavelet function. In wavelet transformation, the terms translational and scale are used, because the time and frequency terms have been used by Fourier transform. Translation is the location of the modulation window when shifted along the signal, related to time information. Scale refers to the frequency, high scale (low frequency) is related to global information from a signal, while low scale (high frequency) is related to detailed information. Continuous wavelet can be mathematically defined as follows:

$$
\gamma(s, \tau)=\int f(t) \psi_{(s, \tau)}^{*}(t) d t
$$

where $\gamma(s, \tau)=$ signal function after transformation; with variables $s$ (scale) and $\tau$ translation as new dimensions; $f(t)=$ original signal before transformation; $\psi_{(s, \tau)}^{*}(t)=$ basic function of wavelet.

Furthermore, the basic principle of discrete wavelet transformation is how to get a representation of the time and scale of a signal using digital filtering and sub-sampling operations. The form of discrete wavelet transformation can be seen in the following equation:

$$
T W D(m, n)=\sum\left(a_{0}^{m}\right)^{-0.5} f(k)\left[\frac{\psi\left(n-k a_{0}^{m}\right)}{a_{0}^{m}}\right]
$$

where TWD = discrete wavelet transform; $\psi=$ wavelet function; $f(k)=$ original signal; $a_{0}^{m}=$ scale constanta; $k a_{0}^{m}=$ translation constatnta; $k, m=$ integer variable.

\subsection{IHACRES}

The IHACRES model (Identification of the Hydrograph and Component Flow from Rainfall, Evaporation and Stream Flow Data Unit) is the result of collaboration between the Hydrology Institute (HI) in the UK and The Center for Resource and Environmental Studies (CRES) at the Australian National University (ANU) [3].

The concept of the IHACRES model is a simplification of the hydrological process where discharge variable is generated from a variable input of rain and climatological factors. According to Ye et al. [4] for the calculation of effective rainfall in the IHACRES model based on the equation:

$$
\begin{gathered}
u_{k}=\left[c\left(\phi_{k}-l\right)\right]^{p} r_{k} \\
\phi_{k}=r_{k}+\left(1-\frac{1}{\tau_{k}}\right) \phi_{k-1} \\
\tau_{k}=\tau_{w} \ell^{\left(0,062 f\left(t_{r}-t_{k}\right)\right)}
\end{gathered}
$$

where $u_{k}=$ effective rain $(\mathrm{mm}) ; r_{k}=$ measured rain $(\mathrm{mm}) ; c=$ mass balance $\left(\mathrm{mm}^{-1}\right) ; l=$ the soil moisture threshold index to produce flow; $p=$ a non-linear time period response. 
Parameters $l$ and $p$ are only used for temporary watersheds (ephemeral), $\phi_{k}=$ soil moisture $(\mathrm{mm}) ; \tau_{k}=$ drying rate; $t_{k}$ measured temperature $\left({ }^{\circ} \mathrm{C}\right) ; \tau_{w}=$ drying rate at reference temperature.

According to Sriwongsitanon and Taesombat [4] in linear modules, rainfall is effectively converted into runoff using a linear relationship. Two components influence the flow, namely quick flow and slow flow. Both parts can be connected in parallel or series. It is recommended to use these two components in parallel, except for semi-arid or ephemeral rivers where one component is usually adequate. Parallel configurations of the two components under time conditions $\mathrm{k}$ for fast flow and slow flow combined to produce runoff are presented in the following formula:

$$
\begin{aligned}
& x_{k}=x_{k}^{(q)}+x_{k}^{(s)} \\
& x_{k}^{(q)}=-\alpha_{q} x_{k-1}^{(q)}+\beta_{q} u_{k} \\
& x_{k}^{(s)}=-\alpha_{s} x_{k-1}^{(s)}+\beta_{s} u_{k}
\end{aligned}
$$

where $x_{k}=$ runoff or discharge $(\mathrm{mm}) ; x_{k}^{(q)}=$ fast flow $(\mathrm{mm}) ; x_{k}^{(s)}=$ a slow flow $(\mathrm{mm}), \alpha_{q}=$ the recession number for fast flow, $\alpha_{\mathrm{s}}=$ the recession number for slow flow; $\beta_{q}=$ the peak response for fast flow; $\beta_{s}=$ the peak response for slow flow. The dynamic response characteristics for fast and slow flow can be calculated using the following formula:

$$
\begin{gathered}
\tau_{q}=\frac{-\Delta}{\ln \left(-\alpha_{q}\right)} \\
\tau_{s}=\frac{-\Delta}{\ln \left(-\alpha_{s}\right)}
\end{gathered}
$$

with $\Delta=$ a period of time; $\tau_{q}=$ the constant of the fast response time (days); $\tau_{s}=$ the slow response time constant (days). Comparison volume for fast flow and slow flow can be calculated using the following equation:

$$
v_{q}=\frac{\beta_{q}}{1+\alpha_{q}}=1-v_{s}=1-\frac{\beta_{s}}{1+\alpha_{s}}
$$

with $v_{q}$ is the comparison volume for fast flow and $v_{s}$ is the comparison volume for slow flow.

\section{Results and discussion}

Wavelet transform consists of several families, namely: Haar, Daubechies (db), Coiflets (Coif), Symlets (Sym), Biorthogonal (Bior), Revers Bior (Rbio), Dmeyer (Dmey). Wavelet family types that are suitable for IHACRES modeling are Haar and Bior wavelet families. Pre-process model development which consists of several levels in the process of modification and decomposition. In this study using Haar level 1 and Bior 1.1 level 1 wavelet transformation models. The type of wavelet family model for input to the IHACRES model as follows: 
Table 1. Type of wavelet transform dan input varaible.

\begin{tabular}{|c|c|c|}
\hline Type of wavelet & Level & Input variable \\
\hline Haar & 1 & Rainfall (I) \\
\hline Haar & 1 & Rainfall (I); Temperature (T) \\
\hline Haar & 1 & Rainfall (I); Discharge (Q) \\
\hline Haar & 1 & $\begin{array}{c}\text { Rainfall (I); Temperature (T); } \\
\text { Discharge (Q) }\end{array}$ \\
\hline
\end{tabular}

In the model calibration for various schemes the type of wavelet family is obtained the effectiveness of the model as shown in the following Table 2.

Table 2. Nash-Sutcliffe value in model calibration.

\begin{tabular}{|c|c|c|}
\hline Input variable & Type of wavelet & Nash-Sutcliffe \\
\hline Rainfall (I) & Haar level 1 & 0.783 \\
\hline Rainfall (I); Temperature (T) & Haar level 1 & 0,782 \\
\hline Rainfall (I); Discharge (Q) & Haar level 1 & 0.787 \\
\hline $\begin{array}{c}\text { Rainfall (I); Temperature (T); } \\
\text { Discharge (Q) }\end{array}$ & Haar level 1 & 0.786 \\
\hline
\end{tabular}

As with Croke et. al. [5], the accuracy evaluation of model using objective functions NashSutcliffe as follows:

$$
R^{2}=1-\frac{\sum\left(Q_{o}-Q_{m}\right)^{2}}{\sum\left(Q_{o}-\bar{Q}_{o}\right)^{2}}
$$

with $Q_{o}$ is the observation discharge $\left(\mathrm{m}^{3} / \mathrm{sec}\right), Q_{m}$ is the calculated discharge $\left(\mathrm{m}^{3} / \mathrm{sec}\right)$, $\overline{Q_{o}}$ is the average of observation discharge.

Table 2 shows that the best model calibration is obtained for the type of wavelet is Haar level 1 , and the input variables are rainfall and discharge. The next step is to verify the results of the model calibration for Haar level 1 wavelet model and input variables are rainfall and discharge. Verification results using the value of the nash-sutclifee result is 0.447 , and the correlation value between the model and observation is 0.737 . The criteria of the correlation coefficient in the verification stage are categorized as strong correlations. The hydrograph representation of the wavelet-IHACRES model is shown in Fig. 2. 


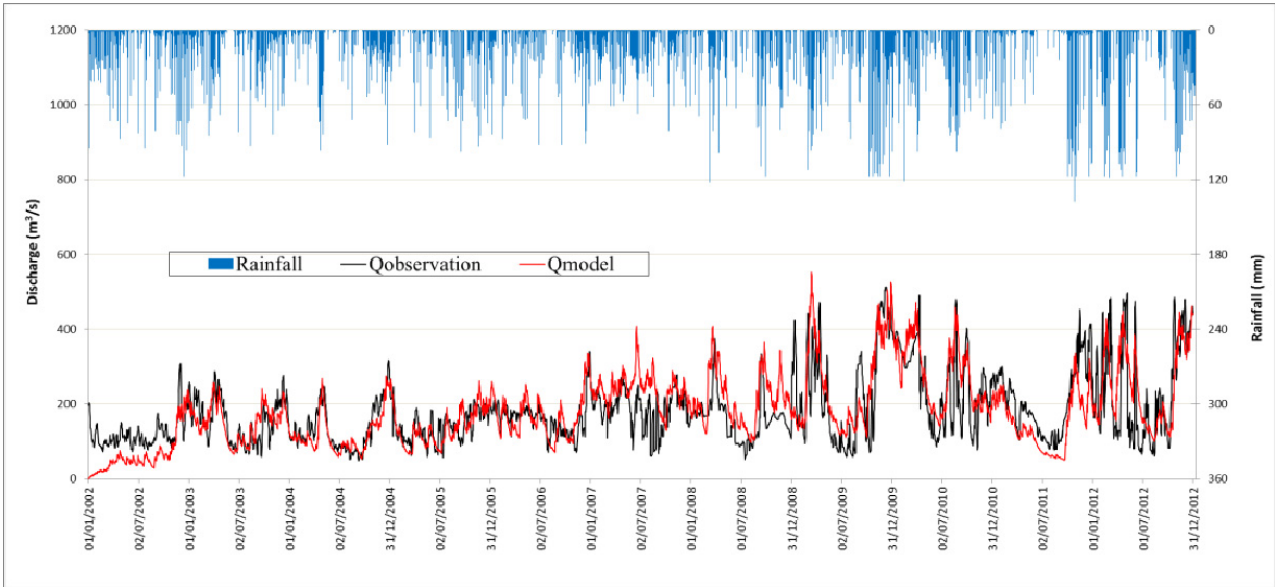

Fig. 2. Hydrograph model and hydrograph observation.

\section{Conclusions}

Based on the study above, it can be concluded as follows. In the verification and simulation phase which gives the best correlation value is the Haar wavelet for input of rainfall and discharge data with a value of 0.674 and a simulation of 0.737 . Based on previous research, this hybrid model provides improved performance estimates of the water availability in the Siak River.

\section{References}

1. Indarto, Hidrologi: Dasar teori dan contoh aplikasi model hidrologi (Bumi Aksara, Jakarta, 2010)

2. M. Fauzi, I. Suprayogi, S. Sutikno, A. Sandhyavitri, E. Riyawan, Matec Web of Conferences 101, (2017)

3. B.F.W. Croke, F. Andrews, J. Spate, S. Cuddy, IHACRES User Guide (The Australian National University, Australia, 2005)

4. N. Sriwongsitanon, W. Taesombat, Kasetsart Journal 45, (2011)

5. B.F.W. Croke, F. Andrews, A.J. Jakeman, S. Cuddy, A. Luddy, Proc. of the $29^{\text {th }}$ Hydrology and Water Resources Symposium (2005) 